\title{
O discurso histórico-literário construído por Tabajara Ruas, em Netto perde sua alma
}

\section{The historical-literary discourse build by Tabajara Ruas, on Netto perde sua alma}

1 Possui Mestrado em Letras - Literatura Comparada, pela UFPel.

E-mail: aninhasm22@gmail.com

Possui Mestrado em Letras - Literatura Comparada, pela UFPel.

E-mail: aluiza.nunes@gmail.com
Ana Cláudia Sampaio Martins ${ }^{1}$, Ana Luiza Nunes Almeida ${ }^{2}$

RESUMO: 0 presente artigo visa entender o entrecruzamento entre literatura e história no romance Netto Perde sua Alma (1995), de Tabajara Ruas. Para tanto, analisaremos a referida obra sob a perspectiva do Novo Romance Histórico e da Metaficção Historiográfica, pois entendemos que ambas teorias se assemelham ao entenderem que o estudo do passado deve ser feito a partir da reflexão crítica que o presente possibilita e, portanto, admitem que não há uma única interpretação acerca dos fatos históricos. Na análise da narrativa e de suas personagens, corroboraremos com esta perspectiva, pois o autor apresenta-nos múltiplos pontos de vista em relação à Revolução Farroupilha e à Guerra do Paraguai.

PalAVRAS-CHAVE: Literatura; História; Novo romance histórico; Metaficção historiográfica.

ABSTRACT: This article aims to understand the intersection between literature and history in the novel Netto Perde sua Alma (1995), by Tabajara Ruas. Therefore, we analyze the novel from the perspective of the New Historical Novel and the Historiographic Metafiction, because we understand that both theories resemble on the understanding concerning the idea that the study of the past has to be done starting from a critical reflection that only the present makes it possible and, therefore, they admit that arendt a single version surrounding the facts. In the analysis of the narrative and her characters, we will corroborate that perspective, because the author presents us multiple points of view regarding Revolução Farroupilha and Guerra do Paraguai.

KEYWORDS: Literature; History; New historical novel; Historiographic metafiction. 
$\mathrm{N}$

este artigo pretendemos refletir acerca do discurso históricoliterário construído por Tabajara Ruas, em Netto Perde sua Alma (1995), confrontando-o com a historiografia oficial. Para tanto, tomamos como introdução as reflexões de Michel Foucault em A Ordem do Discurso (1996), a fim de dissertar sobre o modo como a contemporaneidade entende a História. De acordo com Foucault, os discursos possuem uma força imensurável, uma vez que não apresentam somente os relatos de acontecimentos de uma época, mas também são organizados a partir dos pensamentos ideológicos de quem os escreve. Assim sendo, notamos que, durante muito tempo, a história foi posta em discurso sob a perspectiva das classes dominantes, subordinando todos os seus descendentes a um conhecimento limitado a respeito dos fatos narrados.

Em uma sociedade como a nossa, conhecemos, é certo, procedimentos de exclusão. 0 mais evidente, o mais familiar também, é a interdição. Sabe-se bem que não se tem o direito de dizer tudo, que não se pode falar de tudo em qualquer circunstância, que qualquer um, enfim, não pode falar de qualquer coisa. Tabu do objeto, ritual da circunstância, direito privilegiado ou exclusivo do sujeito que fala: temos aí um jogo de três tipos de interdições que se cruzam, se reforçam ou se compensam, formando uma grade complexa que não cessa de se modificar (FOUCAULT, 1996, p. 9).

Desse modo, o discurso se apresenta como um dispositivo de poder, o qual subverte a realidade, não se limitando apenas em traduzi-la. Entendemos, pois, que a historiografia oficial expõe somente uma parte da história, preterindo outra, possivelmente vivenciada pelas minorias sociais, desfavorecidas de voz na sociedade. Sobre essa questão, Walter Benjamin, em seu ensaio Sobre o Conceito de História (1987), aponta à necessidade de outra escritura da história, a qual não deve se preocupar tão somente em resgatar o passado, precisando incluir nesta rememoração a visão crítica que o presente pode oferecer.

Articular historicamente o passado não significa conhecê-lo 'como ele de fato foi'. Significa apropriar-se de uma reminiscência, tal como ela relampeja no momento de um perigo. Cabe ao materialismo histórico fixar uma imagem do passado, como ela se apresenta, no momento do perigo, ao sujeito histórico, sem que ele tenha consciência disso. 0 perigo ameaça tanto a existência da tradição como os que a recebem. Para ambos, o perigo é o mesmo: entregar-se às classes dominantes, como seu instrumento. Em cada época, é preciso arrancar a tradição ao conformismo, que quer apoderar-se dela (BENJAMIN, 1987, p. 223).

O passado rememorado pela historiografia oficial dá conta das grandes façanhas e personagens históricos ilustres, excluindo todos aqueles que foram oprimidos e marginalizados em determinada época. O discurso praticado é homogêneo e vazio, pois utiliza uma voz una e inquestionável, a qual tenta abranger um período histórico em toda a sua completude. Entretanto, à luz da perspectiva benjaminiana, um período histórico só é digno de atenção se ele estiver ligado ao presente, oportunizando uma crítica, a fim de entender, também, o passado oprimido.

Seguindo essa abordagem, Netto Perde sua Alma apresenta um discurso múltiplo, o qual, mesmo corroborando em alguns momentos com a historiografia oficial, também possibilita que outras personagens -excluídas ou marginalizadas pela história - desenvolvam os seus discursos neste romance. A verdade que é apresentada na narrativa depende de quem a narra, fazendo-nos perceber que não existe uma verdade absoluta que abarque a história em sua totalidade.

Tabajara Ruas escreveu o seu romance sob uma perspectiva contemporânea, narrando alguns fatos históricos sul-rio-grandenses sem 
adotar uma visão estereotipada e, em alguns momentos, questionando e reescrevendo o passado histórico.

\section{A articulação entre literatura e história: o romance frente à história "oficial"}

Os debates sobre a confluência entre os discursos históricos e literários foram intensificados com o surgimento de teorias que questionam a objetividade do historiador e as noções de verdade na história. A partir de então, esta passou a ser pensada como um discurso subjetivo, o qual empreende o território da ficção. Ao entendermos que a história dita "oficial" foi criada a partir de discursos subjetivos, minados de pensamentos e ideologias de quem os propunha, concluímos que os discursos históricos tendem a se confundirem com os ficcionais. Nesse sentido, a proposta de uma revisão da historiografia se tornou oportuna, visto que temos a necessidade de conhecer as mais variadas interpretações do passado; a fim de compreendermos os acontecimentos do presente.

Na concepção de Hayden White (1994), o discurso histórico não pode ser entendido como uma verdade absoluta e, portanto, não se opõe ao discurso literário, já que ambos são construídos a partir de um ponto de vista específico, o qual analisa os fatos de acordo com as perspectivas ideológicas de quem os narra. Desse modo, White diz que:

Houve uma relutância em considerar as narrativas históricas como aquilo que elas manifestamente são: ficções verbais cujos conteúdos são tanto inventados quanto descobertos e cujas formas têm mais em comum com os seus equivalentes na literatura do que com os seus correspondentes nas ciências (WHITE, 1994, p. 98).

Ao questionar o historiador, White põe em dúvida, também, a historiografia "oficial", pois entende que um mesmo evento pode ser contado de várias formas e possuir sentidos diferentes, os quais são determinados pelo historiador quando constrói a sua narrativa; evidenciando, então, que os fatos relatados adquirem sentido no discurso. Nessa concepção, prevê que a escolha dos eventos narrados é manipulada, tanto na história quanto na literatura.

Mikhail Bakhtin (1993), assim como White, acreditava ser possível que um mesmo fato histórico resultasse em diferentes interpretações. Suas reflexões permitiram que o discurso literário deixasse de ser analisado somente pelos aspectos formais, entendendo que as perspectivas ideológicas que o cercam também são importantes para compreendê-lo. No romance bakhtiniano são consideradas as circunstâncias externas (temporais, espaciais, ideológicas) e os elementos linguísticos que as refletem. Assim, é colocado em conexão com o mundo, através de um plurilinguísmo que permite entender o passado sob a ótica do presente. Destoa dos demais gêneros, pois propõe o confronto direto entre a atualidade vivida e o passado representado.

Em seu conjunto, o mundo da grande literatura da época clássica é projetado no passado, no longínquo plano da memória, não dentro de um passado real e relativo, que está ligado ao presente por constantes transições temporais, mas no passado dos valores dos começos e dos fastígios. Este passado está distanciado, acabado e fechado como um círculo. Isto não significa, certamente, que nele não haja qualquer movimento. Ao contrário, as categorias temporais relativas que estão dentro dele são rica e finamente elaboradas (as nuanças de 'antes', 'mais tarde', a sucessão dos momentos, da celeridade, da duração, etc.); está presente uma elevada técnica literária do tratamento do tempo. Mas todos os pontos deste tempo, arredondado e acabado, distam igualmente do tempo real e móvel da atualidade [...]. Todos os gêneros elevados da época clássica, isto é, toda a grande literatura, era construída na área de uma representação distante, fora de qualquer possível contato com o presente e seu caráter inacabado (BAKHTIN, 1993, p. 410-11).

As fronteiras entre os discursos histórico e literário tornaram-se cada vez mais permeáveis desde que a história começou a ser entendida como 
um discurso de ficcionalização da realidade. A interferência do sujeito na produção do discurso passou a ser considerada uma característica imprescindível nas reflexões acerca do passado histórico. O Novo Romance Histórico surgiu, então, para contestar a visão de um passado fechado em si, a qual era defendida por Walter Scott (LUKÁCS, 2011) no Romance Histórico Tradicional. A nova forma de pensar o passado baseia-se na reescrita da história, questionando a versão estereotipada proposta pela historiografia oficial e substituindo-a, com o objetivo de desfazer a visão eurocêntrica imposta ao passado, ao tentar dar conta dos acontecimentos relegados pela historiografia.

Resulta que los investigadores no sólo orientan sus análisis para indicar los momentos en los que las novelas estudiadas borran la frontera entre la historiografía y la literatura o cuestionan la historia 'oficial', sino que se sirven de ambas fórmulas como de etiquetas que deberían despertar el interés de los lectores. $\mathrm{Si}$, como suele pasar en los artículos dedicados a las novelas históricas recientes, las dos fórmulas aparecen juntas, conllevan un mensaje cuya retórica se puede mostrar de la siguiente manera: 1) puesto que no hay frontera entre la historiografía y la literatura, se sugiere que la novela etiquetada tiene igual estatus cognoscitivo que una obra historiográfica; 2) al mismo tiempo, al presuponer que la obra cuestiona la versión 'oficial' de la historia, se asegura que el texto descubre algo radicalmente nuevo sobre el pasado y sobre los mecanismos de la historia, algo hasta ahora bien oculto (GRUTZMACHER, 2006, p. 160).

Grutzmarcher aponta tendências do romance histórico na contemporaneidade, creditando aos escritores contemporâneos uma crítica frente ao discurso da história oficial - a vontade de quebrar com os paradigmas, de ir contra o que dizia a história, para questioná-la, colocar em cheque a versão canônica do passado e subverter a história em prol da crítica. Ele aponta duas tendências que são: a reconstrução do passado dominada pela força centrípeta, que substitui a história oficial pela história criada pelo escritor; e a desconstrução do passado dominada pela força centrifuga, a impossibilidade concreta de reconstruir o passado. Segundo ele, a história pós-oficial, o que é lido no romance, é tão verdadeiro quando o que está nos livros de história.

Assim o texto literário compete com o texto histórico, uma vez que aquilo que é representado nos romances pode ser interpretado como uma faceta da história. A história contida na literatura compete com a história oficial que entra na historiografia, e, portanto, se olha para o passado com a perspectiva do presente, da experiência contemporânea - olha-se o passado a partir do momento da enunciação.

As personagens criadas na ficção do Novo Romance Histórico fogem dos estereótipos históricos, substituindo as convenções tradicionais por paródias e travestimentos, como forma de questionar os padrões sociais impostos. É notável, nesse contexto, as similitudes entre a nova forma de perceber o romance histórico e o conceito bakhtiniano de romance, o qual pretendia parodiar os gêneros predominantes da época. Podemos observar, portanto, que na nova forma de narrar a história, interpretamos a verdade como uma realidade culturalmente constituída. Nesse sentido, não é mais necessário determinar o que é central ou periférico na história ou, então, limitá-la em registrar apenas grandes personagens e acontecimentos, colocando as demais personagens como simples coadjuvantes da trama. Dessa maneira, é substituído "o individual, para o fragmento, para a percepção atomizada do mundo que caracteriza o homem de hoje, na medida em que o autor é um demiurgo que conta a sua versão de uma História possível" (MELLO, apud PELLEGRINI, 1999, p. 116).

As mudanças na forma de analisar o passado oportunizaram a reconstrução de diversos fatos históricos. A partir do Novo Romance Histórico, iniciou-se a problematização da realidade, através de novas interpretações sobre a mesma e, em consequência disso, os acontecimentos e as personagens são construídos de maneira subjetiva, dando a possibilidade 
de múltiplas interpretações, as quais se apoiam na exploração dos detalhes da trama e na humanização das personagens.

A Metaficção Historiográfica, assim como o Novo Romance Histórico, também se sustenta no discurso para articular a literatura com a história; entretanto revisa o passado sob uma perspectiva irônica, sem se comprometer com a verdade, mas, sim, com a verossimilhança que a narrativa busca transmitir.

Não estamos sendo testemunhas de uma degeneração rumo ao hiper-real sem que haja origem ou realidade, mas sim um questiona- mento sobre qual pode ser o sentido 'real' e de maneira podemos conhecê-lo. A função da reunião entre o historiográfico e o metaficcional em grande parte da ficção contemporânea [...] é conscientizar o leitor sobre a distinção entre os acontecimentos do passado que realmente ocorreu e os fatos por cujo intermédio proporcionamos sentido a esse passado, por cujo intermédio presumimos conhecê-lo (HUTCHEON, 1991, p. 281).

Linda Hutcheon (1991) explica que a Metaficção Historiográfica sugere que a verdade e a falsidade não devem ser os pontos de partida para se discutir a ficção, visto que ambas se apoiam na verossimilhança, podendo ser entendidas como construtos linguísticos, igualmente intertextuais, interpretando os textos passados sob a perspectiva do presente. Lembra que o passado empírico só pode ser apreendido através da seleção e do posicionamento narrativo, ou seja, "só conhecemos esses acontecimentos passados por intermédio de seu estabelecimento discursivo, por intermédio de seus vestígios" (HUTCHEON, 1991, p. 131).

A metaficção historiográfica refuta os métodos naturais, ou de senso comum, para distinguir entre o fato histórico e a ficção. Ela recusa a visão de que apenas a história tem uma pretensão à verdade, por meio do questionamento da base dessa pretensão na historiografia e por meio da afirmação de que tanto a história como a ficção são discursos, construtos humanos, sistemas de significação, e é a partir dessa identidade que as duas obtêm sua principal pretensão à verdade (HUTCHEON, 1991, p. 127)
Podemos perceber, portanto, que a literatura e a história se articulam a partir de seus discursos e estes são construídos sob a perspectiva de quem os elabora. Desse modo, a reflexão acerca das ideologias que embasaram um determinado escritor é fundamental para que tenhamos um entendimento mais amplo da obra literária. A literatura, como problematizadora da História, elabora o seu discurso a partir da verossimilhança e, além disso, "as duas são identificadas como construtos linguísticos, altamente convencionalizadas em suas formas narrativas e nada transparentes em termos de linguagem ou de estrutura; e parecem ser igualmente intertextuais, desenvolvendo os textos do passado com sua própria textualidade complexa" (HUTCHEON, 1991, p. 141). Nessa mesma linha de raciocínio encontram-se as reflexões de White, o qual também concebe a história como uma espécie de ficção, ou seja, um discurso narrativo que combina uma série de eventos presumivelmente ocorridos no passado. Para o crítico, o entrecruzamento entre a literatura e a história é cada vez mais evidente, de modo que:

Se há um elemento do histórico em toda poesia, há um elemento da poesia em cada relato histórico do mundo. E isso porque, no relato que fazemos do mundo histórico, somos dependentes num grau em que talvez não o desejemos nas ciências naturais, de técnicas de linguagem figurativa, tanto para a nossa caracterização dos objetos de nossas representações narrativas quanto para as estratégias por meio das quais compomos os relatos narrativos das transformações desses objetos no tempo. E isto porque a história não apresenta objeto que se possa estipular como sendo unicamente seu; ela sempre é escrita como parte de uma disputa entre figurações poéticas conflitantes a respeito daquilo em que o passado poderia consistir (WHITE 1994, p. 115).

O historiador tem por objetivo, pois, arranjar e organizar os eventos identificados no passado, mas isso nunca escapa a subjetividade do sujeito historiador. Por isso, a diferença de maior relevância entre a história e a ficção é que o historiador "encontra" suas histórias e as interpreta, ao passo 
que o ficcionista "inventa" suas histórias a partir de outras. Assim concluímos que, seguindo as ideias de Doctorow, "a história é uma espécie de ficção em que vivemos e esperamos sobreviver, e a ficção é uma espécie de história especulativa pela qual se considera que, em suas fontes, os dados disponíveis para a composição são maiores e mais variados do que supõe o historiador" (HUTCHEON, 1991, p. 149).

\section{0 entrecruzamento entre a literatura e a história em Netto Perde sua Alma}

Em Netto Perde sua Alma, Tabajara Ruas tenta recuperar a história de um dos heróis gaúchos - Antônio de Souza Netto - que lutou na Revolução Farroupilha e, mais tarde, na Guerra do Paraguai; construindo uma narrativa que mescla dados reais e ficcionais. É, antes de tudo, uma obra literária sobre um tempo histórico.

Netto é uma personagem complexa da história do Rio Grande do Sul, a qual fomenta muita especulação a respeito e da sua condição de herói, assim como percebe-se, também, no romance analisado. A narrativa de Tabajara deixa a posição do general Netto um tanto romantizada, sobretudo por ser o próprio general quem narra a obra - é ele quem conta as suas próprias façanhas, levando o leitor a um passeio pela história (pela sua história), mesmo tentando se afastar da visão do Netto narrado em livros de história.

O livro tem início com Netto em um momento de humanismo, morrendo, doente e frágil em uma cama de hospital e, nesta parte, já se percebe a tentativa de representar a personagem a partir da perspectiva de um ser-humano e não o herói de guerra. Em algumas partes, o romance parece ter uma maior preocupação com a subjetividade do general do que com a história na qual ele faz parte, isto é, com os momentos históricos narrados.
Em determinado momento do romance, nota-se a volta da visão do general Netto como herói e o papel que desempenhou na revolução, a partir de uma visão idealizada, como pode-se observar nessa passagem:

Um homem que funda uma república, um homem que escolhe o exílio como casa, um homem que diz olhando nos olhos do Imperado que não tira o chapéu a monarcas não deve ficar recebendo comendas e bênçãos de mandatários de países tais como Brasil, Uruguai, ou Argentina, por mais que tivesse vivido nesses países, e os sofridos na carne, e os amado.

Certamente seria censurado por esse orgulho desmedido, mas se tivessem que censurá-lo por alguma coisa, que o censurassem pelo orgulho (RUAS, 2010, p. 34).

Grande parte dos romances que apresentam as revoluções que aconteceram no Rio Grande do Sul como tema, tendem a mitificar a guerra e suas personagens, transformando-as em heróis e ignorando os aspectos econômicos e políticos que impulsionaram estes mesmos heróis a participarem das batalhas. Em Netto Perde sua Alma, porém, o autor aponta alguns problemas ocasionados pelas revoluções, como, por exemplo, as injustiças cometidas com os negros. No diálogo entre o Sargento Caldeira e Milonga, o escritor explora este tema, a fim de evidenciar o descumprimento da promessa de liberdade aos escravos após o fim da guerra:

- Sargento - disse Milonga -, entramos nesta guerra porque seríamos homens livres quando ela terminasse. Faz um dia que ela terminou. A primeira coisa que fizeram foi tirar nossas armas e botar guardas nos vigiando, como se a gente fosse prisioneiro ou inimigo. [...]

- Mentiram para nós.

- Quem mentiu?

- Todos. Todos mentiram, os republicanos mentiram. Enquanto precisavam da gente para a guerra, falavam em liberdade, igualdade, fraternidade. Quando a guerra terminou, nos entregaram para os imperiais (RUAS, 2010, p, 93-94). 
O escritor elabora um discurso que se opõe à violência da guerra, a qual é refletida em diferentes classes sociais. Apresenta, pois, diversos pontos de vista sobre as revoluções, com intuito de desmistificar a idolatria construída em cima das batalhas gauchescas. Os episódios narrados - mesmo que abordados de forma fictícia - possibilitam uma nova reflexão, mais crítica e menos idealizada, acerca da Guerra do Paraguai e, principalmente, da Revolução Farroupilha. A partir das histórias que compõem o romance, identificamos as motivações que levaram personagens tão distintos à lutarem no mesmo lado na guerra.

O discurso proposto por Tabajara Ruas, em Netto Perde sua Alma, aponta para uma nova interpretação do passado narrado. De maneira fragmentada e ironizando a historiografia oficial, o autor não se dispõe a apresentar uma história única, verdadeira e inquestionável; mas, sim, uma forma possível de compreender os fatos históricos sob a perspectiva do presente. Segue, portanto, o modelo pós-moderno de articular a literatura com a história quando se propõe a "reescrever ou reapresentar o passado na ficção e na história é - em ambos os casos - revelá-lo ao presente, impedi-lo de ser conclusivo e teleológico" (HUTCHEON, 1991, p. 147).

Nesse romance podemos perceber algumas características do Novo Romance Histórico e da Metaficção Historiográfica. Embora estas duas teorias não sejam sinônimas, apresentam várias semelhanças ao representar a história no discurso literário. Em Netto Perde sua Alma, identificamos traços que o inserem no Novo Romance histórico, como, por exemplo, a ficcionalização de personagens históricas. Como já mencionamos anteriormente, não é interesse de Tabajara Ruas criar uma história verdadeira sobre as revoluções gauchescas e, portanto, não podemos entender, também, que o protagonista Antônio de Souza Netto - criado pelo escritor - seja um reflexo do herói gaúcho. Desse modo, verificamos que, tanto a narrativa quanto as personagens que a compõem, não têm compromisso com a verdade, mas podem representar uma das verdades possíveis acerca dos fatos narrados.

Em oposição ao Romance Histórico Tradicional (Lukács, 2011), o qual optava por personagens medianos para assumirem o papel de protagonistas das narrativas; o Novo Romance Histórico põe personagens históricas no centro de suas tramas, as quais "assumem um status diferente, particularizado e, em última hipótese, excêntrico" (HUTCHEON, 1991, p. 150) O protagonista desse romance é retratado de maneira sui generis (MENTON, 1993, p. 43), pois subverte a concepção do caráter heroico imposto pela historiografia oficial aos líderes farroupilhas. O General Netto é construído de forma a expor suas fragilidades e dúvidas, apontando, inclusive, as suas frustrações em relação às guerras que participou.

- Eu matei índios. Matei negros. E matei brancos. Mais do que tudo, matei castelhanos: uruguaios, argentinos, paraguaios, chilenos. Matei portugueses. Matei galegos. Aqui neste quarto eu ficava matutando comigo mesmo nessa gente toda que matei e me dava um peso enorme no coração, sargento. Acho que buscava um pretexto, queria justificar, dar um sentido decente a essa sangueira toda, mas a razão falta quando a gente se lembra de tanto sangue. A gente não quer acreditar que tudo é inútil. A gente quer se lembrar por que matou tanto e pensa nas ideias, nas grandes palavras, e não acha resposta que valha a pena tanto sangue (RUAS, 2010, p. 143)

O humanismo dado ao protagonista propõe uma interpretação ambígua da história narrada, pois, ao mesmo tempo que subverte a historiografia oficial, desmitificando o herói gaúcho; também confirma o seu heroísmo quando entende que todo ser humano é passível de falhas. No romance, o General Netto surge como alguém engajado, procurando ser ético e justo em relação ao desfecho da Guerra dos Farrapos e com a decepção dos lanceiros negros; e, aliado aos delírios e crises de consciência que o atormentam, corrobora com a construção dos heróis gaúchos. No diálogo com o Capitão Osório ficam evidentes as suas frustrações: 
Osório encheu a cuia e estendeu-a para Netto.

- Lamento não poder demovê-lo dessa ideia, general.

- Nas conversas do acordo de paz meus pontos de vista todos foram vencidos, capitão, e eu sempre pretendi ser um home sensato. Não pude fazer nada a respeito dos escravos e isso me corrói. Sei quando estou vencido. Só me resta ir embora.

- A abolição vai chegar, general, assim como a república.

- Disso eu não tenho dúvida, capitão. 0 que me corrói é o destino dos negros que lutaram com os republicanos. Só eles perderam.

Neto apanhou um palheiro já enrolado no bolso da túnica.

- Eles mantiveram o compromisso com a República. Eles não traíram, capitão. Subitamente pareceu ficar deprimido, baixou a cabeça, olhou em torno (RUAS, 2010, p. 99-100).

A relação entre a literatura e a história ganha contornos muito bem delimitados nessa obra, pois Tabajara Ruas investe na ficção para abordar os acontecimentos históricos. A visão do narrador parece limitar-se à visão do protagonista - o General Netto -, figura histórica construída ficcionalmente não como o herói gaúcho, mas, sim, uma personagem composta de virtudes e fraquezas, atribuindo um caráter subjetivo ao romance, através da humanização da personagem histórica. 0 onírico apresenta-se como uma mescla de pesadelos, delírios e alucinações de um moribundo e torna-se fundamental para produzir o efeito de relativização de supostas certezas e verdades. Deste modo, o romance contribui mais para a desconstrução do mito em torno da figura do general, do que propriamente o alimenta.

Outras personagens, contudo, são importantes para apresentar os diferentes pontos de vista que os fatos narrados podem ocasionar. Neste contexto, entendendo que os discursos históricos permitem múltiplas interpretações, principalmente se inseridos na literatura e, com isso, aproximamos Netto Perde sua Alma dos conceitos da Metaficção Historiográfica.
[...] as metaficções historiográficas parecem privilegiar duas formas de narração, que problematizam toda a noção de subjetividade: os múltiplos pontos de vista ou um narrador declaradamente onipotente. No entanto, não encontramos em nenhuma dessas formas um indivíduo confiante em sua capacidade de conhecer o passado com um mínimo de certeza. Isso não é uma transcendência em relação à história, mas sim uma inserção problematizada da subjetividade na história (HUTCHEON, 1991, p. 156).

As personagens Milonga e Sargento Caldeira são exemplos da multiplicidade discursiva, a qual permite diferentes perspectivas acerca do mesmo tema. Intensificam, pois, o conceito de subjetividade proposto pela pós-modernidade, na medida que externam novas formas de compreender os fatos históricos, permitindo reflexões múltiplas sobre os mesmos. 0 jovem Milonga, escravo que se junta voluntariamente ao $1^{\text {o }}$ Corpo de Lanceiros, sob comando do general Netto tem pontos de vista distintos do ideário gaúcho em relação às revoluções gauchescas, visto que sua trajetória vai da euforia inicial diante do contingente farroupilha à total desolação com o desfecho da guerra. Mutilado, tendo perdido um braço, Milonga cobra o general pelo fracasso:

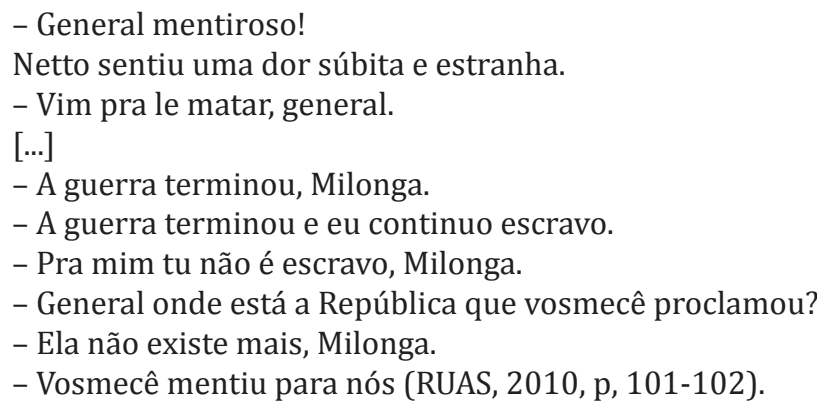

Percebemos, na personagem Milonga, que nem todos entendem as guerras - Revolução Farroupilha e Guerra do Paraguai - de maneira gloriosa, idolatrando aqueles que nelas lutaram. Ao contrário disso, Milonga 
representa muitos que batalharam por acreditar na causa dos republicanos, mas que se decepcionaram com o desfecho e com sua volta à condição de escravo.

Para complementar as características que apontam que o romance Netto Perde sua Alma está inserido na Metaficção Historiográfica, citamos a intertextualidade que está presente na obra. Linda Hutcheon cita que o passado não pode ser revisto de forma ingênua e, portanto, a paródia englobando múltiplos discursos - é um recurso eficaz para rememorar a história.

O que a metaficção historiográfica contesta é qualquer conceito realista ingênuo de representação, mas também quaisquer afirmações textualistas ou formalistas ingênuas sobre a total separação entre a arte e o mundo. 0 pósmoderno é, autoconscientemente, uma arte "dentro do arquivo", e esse arquivo é tanto histórico como literário (HUTCHEON, 1991, p. 165).

Como exemplo de intertextualidade explícita neste romance, podemos citar que Tabajara Ruas "valeu-se do mito de Caronte, o barqueiro dos mortos na mitologia grega e na Divina Comédia, de Dante Alighieri, que transportava em seu barco a alma dos mortos para a travessia do Aqueronte, um dos rios do reino subterrâneo de Hades" (CORNELSEN, 2008).

- 0 canoeiro devia estar aqui.

- Canoeiro?

Netto olhou ao redor, preocupado. Soprava um vento ainda tênue, que começou a interferir na formação compacta da neblina. A praia era comprida e deserta. Além da onipresença dos sapos, o silêncio era completo. Ouviu um leve rumor de água agitada. Firmou os olhos, mas nada era visível. E então, pouco a pouco, do interior da neblina, foi tomando forma, lento e silencioso, longo e escuro, o perfil de uma canoa. Era conduzida por um homem coberto por uma capa negra. 0 homem impulsionava a canoa com uma vara comprida, seguro do rumo, sem pressa (RUAS, 2010, p. 154-155).
Entretanto, o autor não usa o intertexto simplesmente para fazer uma alusão ao mito, mas traz esta referência como forma de satirizar a morte e corroborar a valentia do protagonista, o qual ironiza a própria morte; sendo que, desta forma, entende que "a paródia não é a destruição do passado; na verdade, parodiar é sacralizar o passado e questioná-Io ao mesmo tempo" (HUTCHEON, 1991, p. 165).

A forma que Tabajara Ruas constrói a sua narrativa vai ao encontro do conceito de paródia proposto por Linda Hutcheon, pois, ao mesmo tempo que corrobora com o heroísmo idealizado que as batalhas gauchescas propõem; também evidencia uma subversão a estes valores. Além de apresentar o General Netto como uma personagem ambígua - heroica e problematizada -, a crítica à história oficial também se desdobra na caracterização do major Ramírez, que, apesar de ter cometido várias barbaridades ao longo de sua carreira militar, seria considerado um herói. Próximo ao final do romance, quando o sargento Caldeira está explicando a Netto por que deve matar o major, revela a crueldade e a covardia de Ramírez, enfatizando a mesma ironia já referida de que, apesar disso, ele sairia da guerra como um herói:

- Ele matava crianças, general. E mulheres. E grávidas. E pobres velhos. Eu vi ele mandar abrir uma cova e mandar jogar lá dentro o que restava duma povoaçãozita chamada Ayuí-Chico. Umas setenta pessoas, mais ou menos. Todos pobres e desarmados. E ele dava risadas e se achava um grande herói. Grande Herói do Exército da Tríplice Aliança (RUAS, 2010, p. 144).

Outra característica importante do livro é o tratamento com a linguagem. A forma como Ruas monta a sua obra pode se relacionar com alguns recursos cinematográficos, como a separação de cenas em flashes e também a descrição de cenários, paisagens do campo. Além disso, a estrutura do romance faz com que a ordem cronológica seja subvertida - a ordem dos capítulos e os subcapítulos tornam a narrativa mais próxima da narrativa fílmica, da 
estrutura genérica de um filme, semelhante a um roteiro cinematográfico. A entrada dos capítulos, faz com que o leitor tenha uma pequena visão do que será lido naquela parte, visão do lugar, do tempo cronológico e da hora em que se situa, como nessa parte a seguir:

\section{PARTE V}

PIEDRA SOLA

Dezesseis anos depois: arredores de Taquarembó,

Republica Oriental do Uruguai, 25 de junho de 1861.

Sete horas da manhã (RUAS, 2010, p. 103).

Além das questões citadas ao longo deste artigo, várias outras permitem entender o romance Netto Perde sua Alma à luz do Novo Romance Histórico e da Metaficção Historiográfica. Concluímos, pois, que ambas teorias foram elaboradas para dar conta de ficções de épocas distintas e, portanto, como a obra de Tabajara Ruas situa-se na contemporaneidade, notamos uma tendência a se encaixar de forma mais adequada na Metaficção Historiográfica. O romance segue um movimento duplo de idealização e subversão, em que a caracterização das personagens desencadeia uma relação diferente com a história, a qual é interpretada sob a perspectiva do presente, questionando pressupostos impostos e a legitimidade das fontes históricas, ao realizar uma crítica das versões oficiais e, portanto, aludindo à impossibilidade de se conhecer a verdade absoluta a respeito de um dado acontecimento histórico. O que se percebe, no entanto, é uma busca por novas formas de abordar a história através de uma narrativa de ficção.

\section{Referências}

BAKHTIN, Mikail. Questões de Literatura e Estética; a Teoria do Romance. São Paulo: Hucitec; Unesp, 1993.

BENJAMIN, Walter. Magia e técnica, arte e política. Ensaios sobre literatura e história da cultura. São Paulo: Brasiliense, 1987.
CORNELSEN, Elcio Loureiro. Leituras Contemporâneas da Guerra dos Farrapos na Literatura Sul-rio-grandense. In: Revista Literatura e Autoritarismo: Processos de Identificação e Políticas da (in)diferença, Santa Maria, n. 18, jul.-dez. 2008.

GRUTZMACHER, Lukasz. Las Trampas del Concepto "La Nueva Novela Histórica" y de la Retórica de la Historia Postoficial. In: Acta Poética, México. D.F., v. 27, n. 1, 2006. <http:// www.iifl.unam.mx/html-docs/acta-poetica/27-1/141-168.pdf>.

FOUCAULT, Michel. A Ordem do Discurso. São Paulo: Edições Loyola, 1996.

HUTCHEON, Linda. Poética do pós-moderno. Rio de Janeiro: Imago, 1991.

LUKÁCS, Gyorgy. O Romance Histórico. São Paulo: Boitempo Editorial, 2011.

MENTON, Seymour. La Nueva Novela Histórica de la América Latina. México: Fondo de Cultura Económica, 1993.

PELLEGRINI, Tânia. A ficção brasileira hoje: os caminhos da cidade. In: Olhar - Revista do CECH (Centro de Ciências Humanas) da UFSCar, São Carlos, ano 1, n. 2, dez. 1999.

RUAS, Tabajara. Netto Perde sua Alma. Rio de Janeiro: Record, 2010.

Recebido em dezembro de 2015

Aceito em abril de 2016 